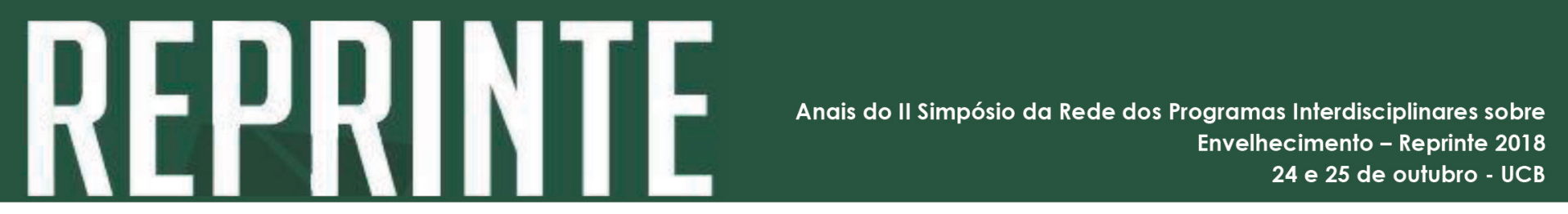

http://dx.doi.org/10.5335/rbceh.v16i1.9913

\title{
20) Relacionamento amoroso no envelhecimento: empecilhos, saúde e qualidade de vida. Uma reflexão por "nossas noites"
}

\author{
Andréa Paula Severiano'; Renata Fialho de Menezes Araújo'; \\ Maria Liz Cunha de Oliveira ${ }^{2}$; Karla Helena Coelho Vilaça e Silva ${ }^{2}$
}

\section{Resumo}

"Nossas Noites" de 2017 é um longa-metragem adaptado do livro de Kent Haruf e narra a história de amor entre os idosos Addie Moore e Louis Waters e as barreiras para tornar possível esta relação. Método: Análise crítica com aporte em estudos atuais voltados às temáticas inseridas no filme sendo que a análise do conteúdo abarcará a identificação do tema principal; síntese da história; decomposições da cena central e adjacentes. Objetivos: refletir sobre os pontos abordados no filme que trazem implicações, dilemas e dificuldades de uma nova relação amorosa entre idosos e os fatores benéficos ou maléficos a sáude. Obra Cinematográfica: abordaram questões como o medo a novos relacionamentos, a aceitação familiar e social, a solidão, o relacionamento entre filhos e netos frente a novos parceiros, o ambiente domiciliar e a tecnologia a partir da contribuição do filme que forneceu quando retratou essas questões o estímulo a uma maior discussão sobre o relacionamento amoroso na terceira idade e as barreiras que enfrentam para vivenciá-la.

Palavras-chave: cinema; amor entre idosos; solidão na velhice; sexualidade no envelhecimento; gerontecnologia.

\section{Introdução}

“Nossas Noites de 2017" é um longa-metragem adaptado do livro de Kent Haruf, que narra à história de amor de Addie Moore e Louis Waterse e as barreiras vivenciadas para tornar possível esta relação depois dos 60 anos.

1 Mestrandas no Programa de Pós-Graduação em Gerontologia da Universidade Católica de Brasília. Endereço para correspondência: QS 07 Lote 01 - EPCT - 71966-700 - Águas Claras - Taguatinga - DF. Emails (na ordem em que aparecem): profandreaps@gmail.com; refimear@yahoo.com.br

2 Professoras do Programa de Pós-Graduação em Gerontologia da Universidade Católica de Brasília. Emails (na ordem em que aparecem): lizcunhad@gmail.com; kavilaca@yahoo.com.br 


\section{Objetivos}

Refletir sobre os pontos abordados que trazem implicações, dilemas e dificuldades aos novos relacionamentos entre idosos, bem como fatores que condicionam e determinam a saúde deles.

\section{Métodos}

Análise cinematográfica que trata sobre o relacionamento amoro depois dos 60 anos, voltados às temáticas inseridas no filme.

\section{Resultados}

Verificou-se que muitos são os empecilhos quando idosos vivenciam um novo relacionamento amoroso, como a aceitação familiar e social e o medo a novas experiências, contudo, a cena do filme em que a tecnologia é inserida no cotidiano deles como ferramenta de aproximação, possibilitou uma quebra de paradigmas do imaginário acerca do assunto, e denota que o amor é possível em qualquer idade.

\section{Conclusão}

O filme foi simples, objetivo e trabalhou com questões que refletem na vida social, nas limitações físicas bem como na saúde mental dos idosos, possibilitando assim uma maior discussão sobre o relacionamento amoro entre pessoas mais velhas.

\section{Amortive relationship in aging: obstacles, health and quality of life. A reflection on "our nights"}

Keywords: cinema; love among the elderly; loneliness in old age; sexuality in aging; gerontecnologia. 